\title{
Application of Numerical Simulation on the Manufacturing Process Qualification of Nuclear Power Plant Steam Generator Tube-sheet
}

\author{
Shao Jun ZHANG ${ }^{1, a}$, Shu Hua LIANG ${ }^{2}$, Wen Bin YANG ${ }^{1}$, Zhao LIU ${ }^{1}$ and Dong Hai ZHAO ${ }^{1}$ \\ ${ }^{1}$ Equipment Supervision Research Centre, Suzhou Nuclear Power Research Institute Co. LTD, Suzhou 215004, China \\ ${ }^{2}$ Manufacturing Process Qualification Centre, CGNPC, Suzhou 215004, China
}

\begin{abstract}
Nuclear power plant key parts-steam generator (SG) tube sheet forging operate in harsh environment, so it has high requirements for internal quality. According to RCC-M specification requirements (take CPR1000 reactor type for example), the manufacturer should carry out workshop qualification and part process qualification before delivery product manufacturing. It is commonly used that centre compaction process and conical plate upsetting process regard as two kinds of large forging upsetting ways. The numerical analogue simulation has been carried out on nuclear power large tube sheet forgings using France Forge simulation software. The results show that: when the same pressure size, 3-direction compressive stress in the core of the billet always exist in the process of upsetting using centre pressing process, and the strain create in the central of the billet, but stagnant zone exist on the bottom and end plane; tensile stress in the core of the billet always exist in the process of upsetting using conical plate upsetting process, it will force the billet that contact with conical plate to deform, so eliminate stagnant zone, but effective deformation don't produce in the central of the billet. The conical plate continue press for conical plate upsetting process, tensile stress in the core of the billet disappear, and then gradually change into pressure stress, then tensile stress is generated at the bottom, finally tensile stress disappear and 3-direction compressive stress exist in the core of the billet.
\end{abstract}

\section{Introduction}

Steam Generator(SG) tube sheet forging for pressurized water reactor(PWR) nuclear power plant is a typical pancake forging, long-term operate in harsh environment with high temperature and high pressure. Thus it plate strength greatly weakened. Tube sheet will aggregate rather large internal stress, which will cause stress concentration on the crack tips, in particular, could have severity hydrogen damage in hydrogen-rich zone. Therefore, tube sheet forging must first ensure the purity of the molten steel in the manufacturing process. Secondly, it need adopt effective compaction method. In addition, it is difficult to compact in the centre of the tube sheet forgings and exceed the standard requirement easily in the ultrasonic testing [1-6].

As a key component of PWR nuclear power plant, SG tube sheet forging should follow the standard requirements of RCC-M. Before the formal part manufacturing, the manufacturer's workshop evaluation and part manufacturing process qualification are carried out according to the requirements of RCC-M M140, to verify the manufacturing factory technical ability and part whole/inner quality can meet the design and nuclear safety requirements [5].

At present, a big problem still present about tube sheet centre compaction. It is mostly that centre boss compaction and cone plate upsetting in the prior art. This paper only conducts analogue simulation and comparison about two compaction processes.

\section{Introduce two compaction processes}

\subsection{Centre boss compaction process}

\footnotetext{
${ }^{\mathrm{a}}$ Corresponding author: zhangshaojun@cgnpc.com.cn
}

Central boss compaction technology is first rotary pressure on the billet bottom end around, leaving a boss in the middle of the billet, the size of boss and billet into a certain proportion, then flat middle boss, on the end of the billet(top end) also performs the same operation. The process can form a similar effect-forging shell, thereby enhancing the compaction effect [7].

\subsection{Conical plate upsetting process}

The conical plate upsetting process first shallow recessing the bottom end of the billet with conical plate, conical plate pressure volume and billet height into a certain proportion, on the end of the billet also performs the same operation. The process can effectively improve the forging internal stress state, force hard deformation zone to change $[8,9]$.

\section{Design model and set up boundary parameters}

\subsection{The establishment of model}

Establish the billet and upper/lower mould model using 3D drawing software (figure 1), and save the file in a certain format, such as .stl, .may, .dou etc. Then import the file to forge software (France transvalor company) to compute.

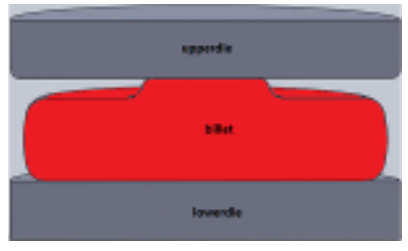

(a) center boss compaction

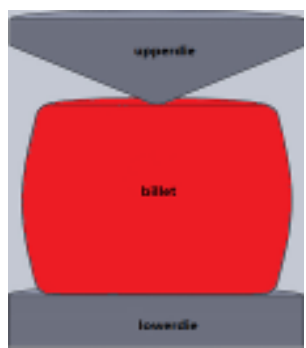

(b)conical plate upsetting
Figure 1. 3D model building 


\subsection{Set up boundary parameters}

The materials $18 \mathrm{MND} 5$ is used for PWR nuclear power plant SG tube sheet [10], which comes from material database supplied by software company. Its main chemical composition is shown in table 1 . The upper die and lower die are set to the rigid body in the whole simulation process. The whole model is divided into network structure consisted of many triangles and tetrahedron [11]. The main simulation parameters and boundary conditions are shown in table 2 .

Table 1. 18MND5 chemical composition

\begin{tabular}{l|l|l|l|l|l|l|l}
\hline Element & $\mathrm{C}_{\max }$ & $\mathrm{Mn}$ & $\mathrm{Si}$ & $\mathrm{P}_{\max }$ & $\mathrm{S}_{\max }$ & $\mathrm{Mo}$ & $\mathrm{Ni}$ \\
\hline Content $\%$ & 0.20 & $1.15-$ & $0.10-$ & 0.012 & 0.012 & $0.45-$ & $0.50-$ \\
& & 1.60 & 0.30 & & & 0.55 & 0.80 \\
\hline
\end{tabular}

Table 2. Simulation parameters and boundary conditions

\begin{tabular}{|c|c|c|c|c|c|}
\hline \multicolumn{6}{|c|}{ billet } \\
\hline \multirow{2}{*}{$\begin{array}{l}\text { Initial } \\
\text { temperature } /{ }^{\circ} \mathrm{C}\end{array}$} & \multirow{2}{*}{$\begin{array}{l}\text { Average } \\
\text { mesh } \\
\text { size } / \mathrm{mm}\end{array}$} & \multicolumn{2}{|c|}{ Initial height $/ \mathrm{mm}$} & \multicolumn{2}{|c|}{ Final height $/ \mathrm{mm}$} \\
\hline & & $\begin{array}{l}\text { Center } \\
\text { boss }\end{array}$ & $\begin{array}{l}\text { Conical } \\
\text { plate }\end{array}$ & $\begin{array}{l}\text { Center } \\
\text { boss }\end{array}$ & $\begin{array}{l}\text { Conical } \\
\text { plate }\end{array}$ \\
\hline 1250 & 20 & 1050 & 2200 & 850 & 2000 \\
\hline \multicolumn{6}{|c|}{ Upperdie/lowerdie } \\
\hline \multirow{2}{*}{$\begin{array}{l}\text { Initial } \\
\text { temperature } /{ }^{\circ} \mathrm{C}\end{array}$} & \multirow{2}{*}{$\begin{array}{l}\text { Upperdie } \\
\text { press/T }\end{array}$} & \multirow{2}{*}{\multicolumn{2}{|c|}{$\begin{array}{l}\text { Upperdie } \\
\text { depress } \\
\text { rate } /(\mathrm{mm} \cdot \mathrm{s}-1)\end{array}$}} & \multicolumn{2}{|c|}{ stroke $/ \mathrm{mm}$} \\
\hline & & & & $\begin{array}{c}\text { Center } \\
\text { boss }\end{array}$ & $\begin{array}{c}\text { Conica } \\
\text { plate }\end{array}$ \\
\hline 25 & 15000 & 15 & & 200 & 200 \\
\hline
\end{tabular}

\section{Results and analysis}

\subsection{Stress analysis}

Figure 2 shows a longitudinal section variation process of stress by using the centre boss compaction technology. It can be seen that there has been greater compressive stress (up to $60.3 \mathrm{MPa}$ ) in the centre boss upsetting process, and at the same time the heart of tube sheet billet always maintain the compressive stress, force is in good condition. The compressive stress extreme value appears in the upper die stroke $200 \mathrm{~mm}$, with a maximum of $16.1 \mathrm{MPa}$ in the central axis region.
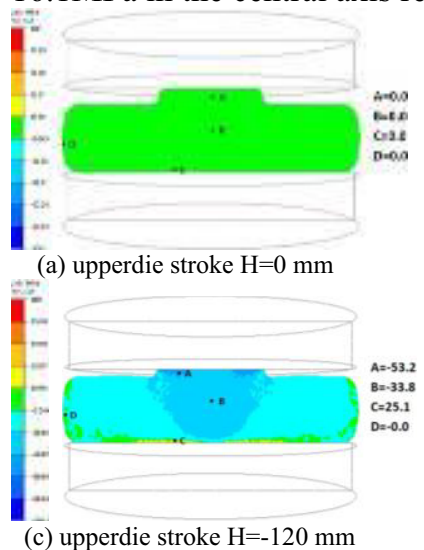

(b) upperdie stroke $\mathrm{H}=-60 \mathrm{~mm}$

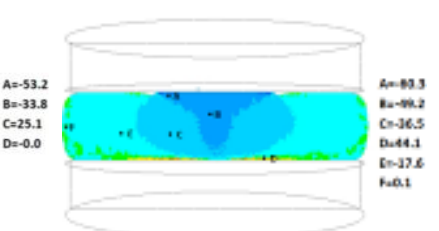

(d) upperdie stroke $\mathrm{H}=-200 \mathrm{~mm}$

Figure 2. Stress analysis of center boss compaction process (Unit: MPa)

Figure 3 shows a longitudinal section variation process of stress by using the conical plate upsetting technology. From figure 3 can be seen, tube sheet billet internal stress is changing constant with the conical plate under pressure. The area near the conical plate produces compressive stress (region A), but there has been tensile stress near billet heart ( $\mathrm{C}$ area of figure3 (b)), and the area is gradually moving down accompanied by a trend of expansion, eventually together with the tensile stress area of billet lower end face. The tensile stress extreme value appear in the conical plate pressure stroke $122 \mathrm{~mm}$ under pressure process, the maximum tensile stress $16.1 \mathrm{MPa}$, and the maximum tensile stress has always been located in the central axis of the billet at any time.

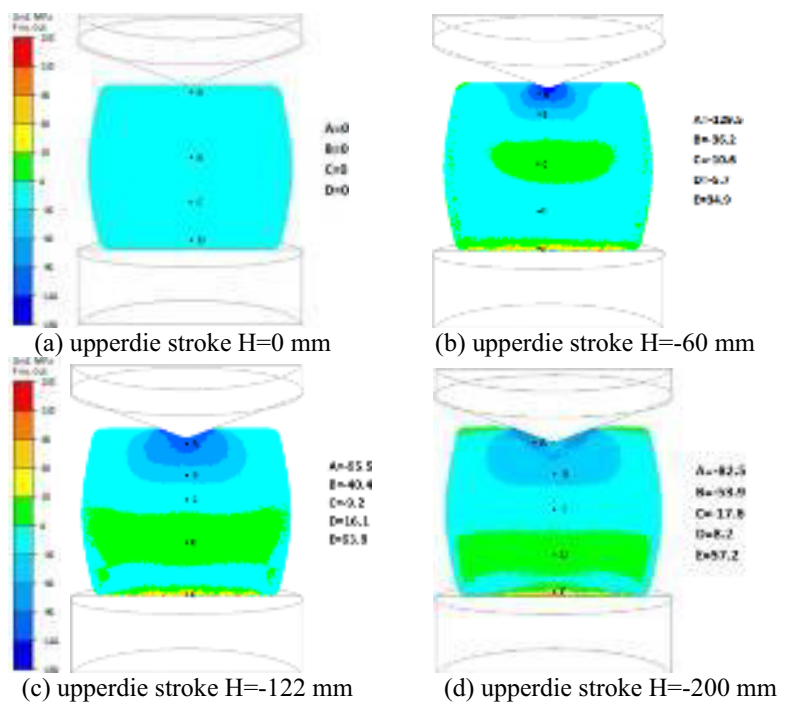

Figure 3. Stress analysis of concial plate upsetting process (Unit: $\mathrm{MPa}$ )

\subsection{Equivalent strain analyses}

Figure 4 show the equivalent strain change process of two upsetting compaction processes. As we can see, the range of the deformation of central boss process can be effectively delivered to the heart region of the billet under the same pressure stroke, but there has still stagnant zone contacted with upper and lower end plane, as shown in figure 4 (b). The range of the deformation of conical plate upsetting process mainly gathers near the top point of the conical plate, as shown in figure4 (d).

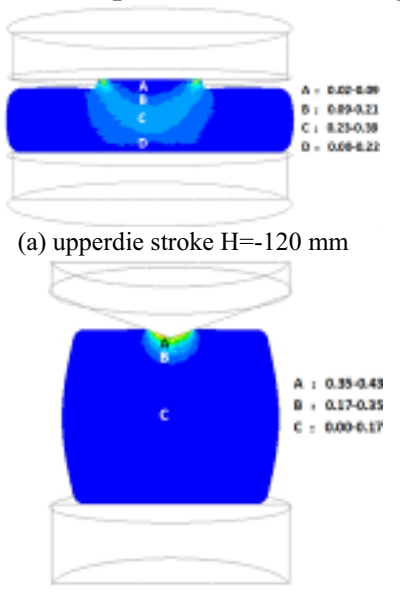

(c) upperdie stroke $\mathrm{H}=-120 \mathrm{~mm}$

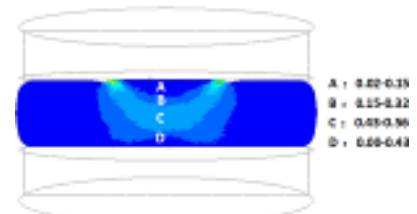

(b) upperdie stroke $\mathrm{H}=-200 \mathrm{~mm}$

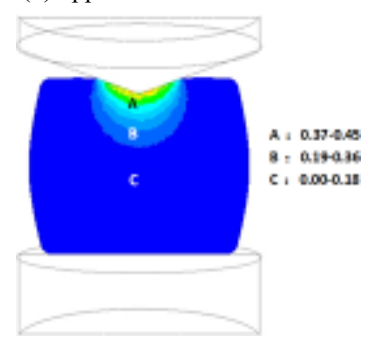

(d) upperdie stroke $\mathrm{H}=-200 \mathrm{~mm}$
Figure 4. Billet equivalent strain analysis of two compaction processes 


\section{Optimization of conical plate upsetting process}

Due to the billet core has been tension stress in upsetting process (pressure stroke $200 \mathrm{~mm}$, reduction rate of $9 \%$ ), and the core has not produce effective deformation, so it need further optimize conical compaction process. When the conical plate continues under pressure (pressure stroke $298 \mathrm{~mm}$, reduction rate of $13.5 \%$ ), billet heart tensile stress all disappear into compressive stress, but the edge zone of the billet produces tensile stress (minor stress value, about $18 \mathrm{MPa}$ ), as shown in figure 5(a). When under pressure reduction rate of $14.3 \%$ (pressure stroke $315 \mathrm{~mm}$ ), the inner of billet produces larger three direction compressive stress at the moment, the maximum tensile stress close to the core of billet is up to $100 \mathrm{MPa}$, as shown in figure 5 (b). But when continue to press down to $14.4 \%$ (pressure stroke $317 \mathrm{~mm}$ ), and tensile stress appear in the edge of billet and near the outer circle, as shown in figure 5 (c). Continue to pressure reduction rate of $26.6 \%$ (pressure stroke $585 \mathrm{~mm}$ ), the tensile stress disappear, meanwhile the core produce larger three direction compressive stress which the value exceeds $100 \mathrm{MPa}$, as shown in figure $5(\mathrm{~d})$.

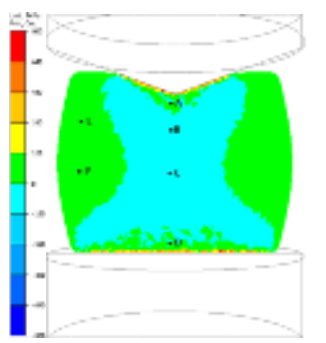

(a) upperdie stroke $\mathrm{H}=-298 \mathrm{~mm}$

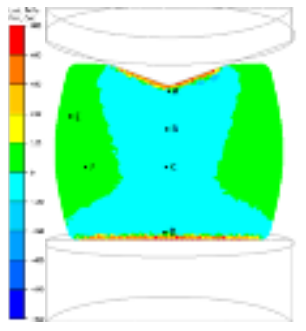

(c) upperdie stroke $\mathrm{H}=-317 \mathrm{~mm}$

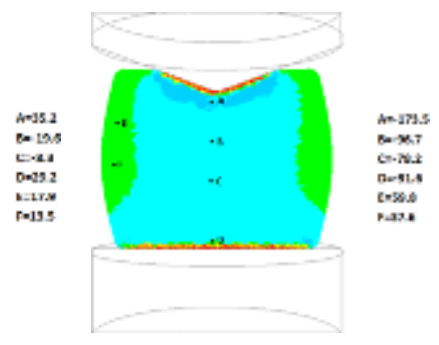

(b) upperdie stroke $\mathrm{H}=-315 \mathrm{~mm}$

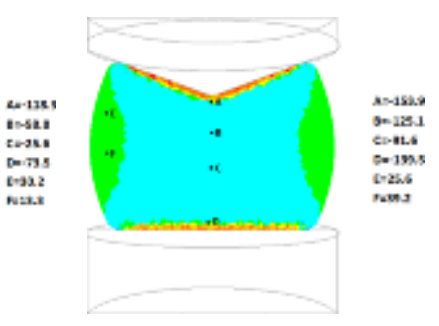

(d) upperdie stroke $\mathrm{H}=-585 \mathrm{~mm}$
Figure 5. Billet stress analysis after conical plate optimization (Unit: MPa)

Figure 6 shows billet effective strain change process following billet under pressure stroke $298 \mathrm{~mm}, 315 \mathrm{~mm}$, $317 \mathrm{~mm}$ and $585 \mathrm{~mm}$. We can see that the deformation range of the billet constantly expand with conical plate under pressure, billet strain of conical top zone gradually increase and the effective deformation transfer to the core area of the billet. Combined with the analysis of billet deformation stress, the core zone of the billet accumulates certain tensile stress and the smaller effective strain when too small pressure stroke, so the effect of the billet core compaction is poor. When pressure amount is large, although the tensile stress of the billet core zone disappear and the larger effective strain, but it is not good for tube sheet forming and the final plate upsetting operation. Therefore, considering the actual production condition of the manufacturing plant, the factory should be comprehensive consideration combined with the stress and strain condition of the billet core and select the appropriate pressure stroke if the factory manufactures tube sheet using conical plate upsetting compaction technology.

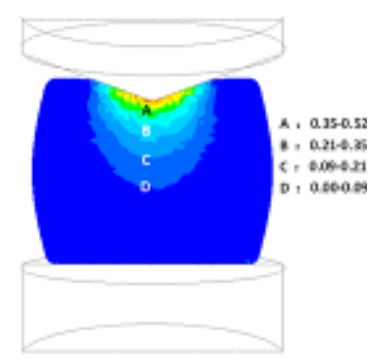

(a) upperdie stroke $\mathrm{H}=-298 \mathrm{~mm}$

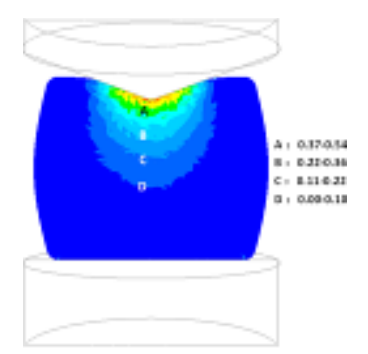

(b) upperdie stroke $\mathrm{H}=-315 \mathrm{~mm}$

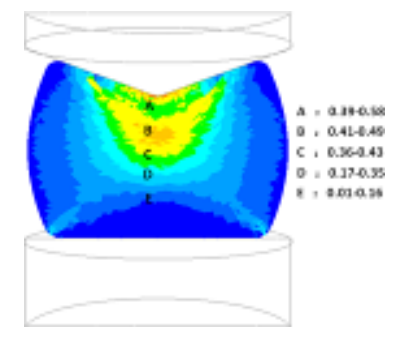

(c) upperdie stroke $\mathrm{H}=-585 \mathrm{~mm}$

Figure 6. Billet strain analysis of conical plate optimization

\section{Actual result verification}

The tube sheet forgings which two compaction processes produced are dissected and evaluated. The tube sheet is divided into 4 blocks according to the center symmetry, and is divided into 8 players parallel to the upper/lower end face, take off 4 layers to carry out mechanical properties test (as shown in figure 7). The tensile experiment is conducted using the above all samples and qualified test machine, and the test results are shown in table 3. It can be seen that Tube sheet produced by two kinds of compaction technology show different performance distribution rule. The tube sheet with central boss compaction technology has equal strength at the surface and the centre area, although there is a decreasing trend, but no significant weakening. The tube sheet with conical plate upsetting process has significant strength weaken from the surface to the core area, it is poor for tube sheet core zone compaction effect, do not get 
effective improvement. As a result, the actual product test results are consistent with the simulation results.
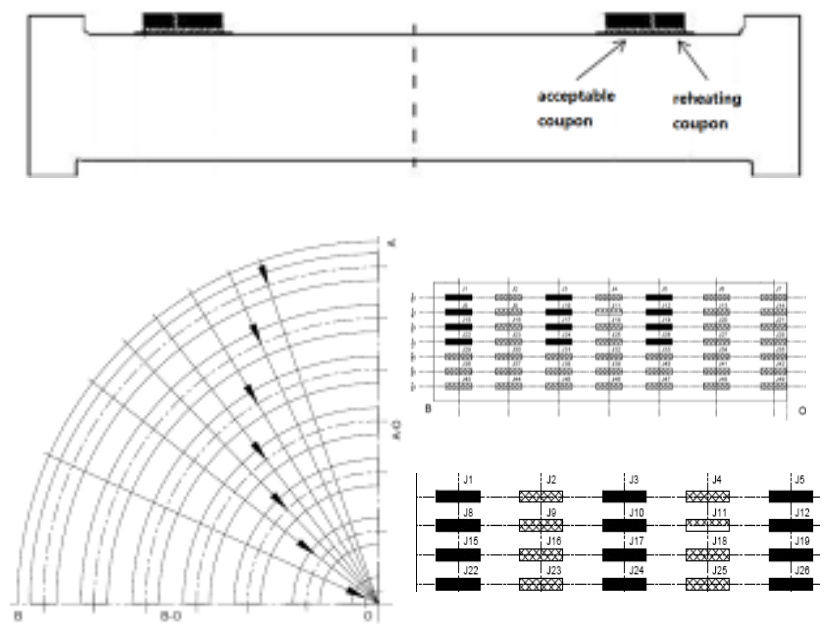

Figure 7. Sketch of tube sheet

Table 3. Test results of two compaction process

\begin{tabular}{l|l|l|l|l}
\hline \multirow{2}{*}{} & \multicolumn{2}{|c|}{ Central boss } & \multicolumn{2}{c}{ Conical plate } \\
\cline { 2 - 5 } & $\sigma 0.2 / \mathrm{MPa}$ & $\sigma \mathrm{b} / \mathrm{MPa}$ & $\sigma 0.2 / \mathrm{MPa}$ & $\sigma \mathrm{b} / \mathrm{MPa}$ \\
\hline 0(surface) & $479 / 396$ & $605 / 556$ & $495 / 414$ & $635 / 582$ \\
t/8(J5) & $480 / 407$ & $604 / 550$ & $460 / 388$ & $620 / 571$ \\
t/4(J12) & $472 / 395$ & $599 / 545$ & $471 / 396$ & $595 / 549$ \\
$3 \mathrm{t} / 8(\mathrm{~J} 19)$ & $477 / 402$ & $603 / 560$ & $443 / 382$ & $587 / 540$ \\
t/2(J26) & $465 / 389$ & $593 / 552$ & $444 / 370$ & $589 / 545$ \\
\hline
\end{tabular}

\section{Application of the simulation results}

The simulation results of the tube sheet compaction can be used to guide the manufacturing process qualification, such as sampling plan, feasibility analysis of the forging process. It is found that the weak parts should increase the test items, sampling quantity, comprehensive anatomy inspection means and to verify overall quality of the tube sheet forgings. When conical plate upsetting process is used, the billet center has not produced effective deformation and tensile stress, so the region as a key test zone in the forming process. When central boss compaction process is used, there has still stagnant zone contacted with upper and lower end plane, add to low structure density, there can cause a certain influence on the mechanical properties, so this region as the focus of the test target.

\section{Conclusions}

(1) The results show that the billet core with central boss compaction technology has keep 3-D compressive stress under the upsetting process in the absolute pressure stroke, and heart area has certain deformation, but upper/lower have stagnant zone.

(2) The billet with conical plate upsetting technology has keep tensile stress under the upsetting process, and heart area has certain deformation, but upper/lower have stagnant zone. Although the billet has certain deformation with the conical top point area, stagnant deformation zone has been improved and eliminated, but there has not been effective deformation in the center region of the billet.

(3) It is need to optimize conical plate upsetting process. When the conical plate continues under pressure (reduction rate of $13.5 \%$ ), billet heart tensile stress all disappear into compressive stress, but the edge zone of the billet produces tensile stress. When under pressure reduction rate of $14.3 \%$, the inner of billet produces larger three direction compressive stress at the moment. But when continue to press down to $14.4 \%$, and tensile stress appears in the edge of billet and near the outer circle. Continue to pressure reduction rate of $26.6 \%$, the tensile stress disappear, meanwhile the core produce larger three direction compressive stress.

(4) The simulation analysis results can be used to guide the manufacturing process qualification, and can also test and verify weak areas targeted, can not only examine overall quality of tube sheet forgings and but also reduce the cost of testing.

\section{References}

1. Han J T, Zhang Y J, Zhao Z L, et al. The research of the upsetting process for controlling the inclusion defects in heavy disk forgings [J]. Heavy casting and forging, 2007, 1:1-5.

2. Zhang H, Liu D F. Scrap analysis about large forging of pipe plate $[\mathrm{J}]$. Chinese journal of mechanical engineering, 2002, 38(1): 138-141.

3. Kan Y Q, Liang S H, Liu L, et al. Study on quality control of heat treatment for steam generator tube sheet forging $[\mathrm{J}]$. Hot working technology, 2010, 39(4): 159-161.Luigi T.De Luca, Propulsion physics (EDP Sciences, Les Ulis, 2009)

4. Shanghai power equipment research institute. PWR nuclear island main equipment materials and welding [M]. Shanghai scientific and technological literature press.

5. Kan Y Q, Huang D P, Zhang S J, et al. Study meaning of manufacturing process qualification assessment method of nuclear island large-sized casting and forging parts $[\mathrm{J}]$. Hot working technology, 2010, 39(1): 53-55.

6. Jin Z H, Guo W. Application of homogenization theory in study on tube-sheet $[\mathrm{J}]$. Journal of Shenyang institute of chemical technology, 2007, 21(1):29-31.

7. Shi R G, Gao Q, Yan X P, et al. Manufacturing process of Large-scale heat exchanger SA765- II tube sheet [J]. Hot working technology, 2012, 41(19): 133-135.

8. Deng D M, Liu Z B, Ni L Y. Numerical simulation of the new technical for upsetting a cylinder between two cone plates $[\mathrm{J}]$. Forging \& Stamping Technology, 2005, 3:22-26.

9. Liu Z B, Ni L Y, Liu G H. New theory and technology of heavy forgings deformation [M]. China machine press, 2009. 
10. Design and construction rules for mechanical components of PWR nuclear islands (RCC$\mathrm{M})[\mathrm{S}]$. French association for design, construction and in-service inspection rules for nuclear island components (AFCEN):Edition 2000 \& addendum June 2002.

11. Zhang S J, Liang S H, Liu Z . Numerical simulation and research of two kinds of compacting process for nuclear power large tube sheet forgings $[\mathrm{J}]$. Hot working technology, 2013, 42(13):102-105. 